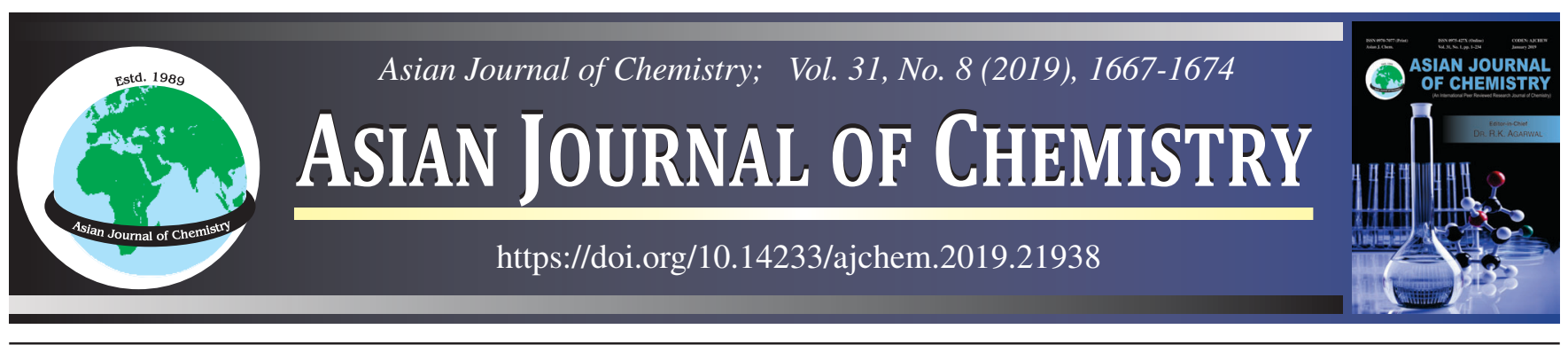

\title{
Adsorption Equilibrium and Kinetic Studies of Effect of ortho-Substitution to Benzoic Acid in Aqueous Phase Using Granular Activated Carbon
}

\section{Roy George}

Department of Chemistry, S.F.S. College, Seminary Hills, Nagpur-440006, India

Corresponding author: E-mail: georgeroysfs@gmail.com

Received: 16 January 2019;

Accepted: 8 March 2019;

Published online: 28 June 2019;

AJC-19434

Adsorption equilibrium and kinetics studies of effect of ortho-substituted benzoic acid in aqueous phase using granular activated carbon were investigated. The granular activated carbon (GAC) obtained from bituminous type coal having a surface area of $998 \mathrm{~m}^{2} / \mathrm{g}$ and loosely bounded and open pores morphology. The adorbates selected for this study was benzoic acid and its ortho-derivatives namely; salicylic acid, phthalic acid and $o$-toluic acid. The solubility of adsorbate in solvent affected the adsorption behaviour more pronouncly. The order of adsorption for adsorbates was found to be as: benzoic acid $>$ salicylic acid $>o$-toluic acid $>$ phthalic acid.

Keywords: Adsorption equilibrium, Kinetic study, Activated carbon, Benzoic acid.

\section{INTRODUCTION}

The phenomenon of adsorption is most widely employed for separation, treatment of waste effluent, refrigeration, environmental pollution control, etc. [1-3]. Organic compounds such as aniline, benzoic acid, aldehydes, etc. are common organic pollutants, need to be removed from wastewater as these compounds posses carcinogenic characteristics [4-6]. Use of activated carbon by means of adsorption for the purpose of removal of organic pollutants are widely used [7-9].

Adsorption is a time dependent process and the knowledge of adsorbate uptake rate and equilibrium is imperative for evolution and design of batch, fixed bed fluidized bed reactor [10-17]. The knowledge of relevant reaction mechanism, interparticle micro-transport processes and reaction dynamics will afford opportunity for evolution of rational process design and optimization procedures of sufficiently wide applicability. Chemical factors associated with the adsorbates are branching and functional group. The physical factors associated with the experimental systems are temperature, initial adsorbate concentration, contact time, linear velocity and presence of suspended solids [18].

Limited literature is available regarding the adsorption of benzoic acid and its ortho-derivatives. Many a time ecological balance is not disturbed directly through the discharge of benzoic acid, but in waste containing discharge rich in toluene the possibility arise of production of benzoic acid in primary oxidation process employed by treatment plants [19]. Salicylic acid is mostly used as medicine, however as a topical agent and a $\beta$-hydroxy acid, salicylic acid is capable of penetrating and breaking down fats and lipids, causing moderate chemical burns of the skin at very high concentrations. It may damage the lining of pores if the solvent is alcohol, acetone or an oil. Higher concentration may generate situation where heamodialysis is required [20]. Similarly, phthalic acid is majorly used in plastic industry even short term exposure of which may causes eye irritation, injuries in respiratory track and epidermal level of skin.

The adsorbate chosen for present work were benzoic acid and its ortho-derivatives i.e. salicylic acid, phthalic acid and $o$-toluic acid. The present study is dedicated to understand the effect of substitution at $o$-position to benzoic acid in its aqueous phase on granular activated carbon (GAC). Industrially important processes are often concerned with more than one adsorbate species therefore both mono-and bi-solute systems have been analyzed.

\section{EXPERIMENTAL}

Double distilled water was used for the study obtained from laboratory set up. The adsorbate chosen for present work were

This is an open access journal, and articles are distributed under the terms of the Attribution 4.0 International (CC BY 4.0) License. This license lets others distribute, remix, tweak, and build upon your work, even commercially, as long as they credit the author for the original creation. You must give appropriate credit, provide a link to the license, and indicate if changes were made. 
benzoic acid and $o$-substituted benzoic acid i.e. salicylic acid, phthalic acid and $o$-toluic acid obtained from E-Merck. The adsorbent system used for the study was granular activated carbon (GAC) obtained from Calgon Co-operation U.S.A.

Preparation of stock solutions: A $0.02 \mathrm{M}$ stock solution of benzoic acid was prepared by dissolving $2.44 \mathrm{~g}$ of benzoic acid in distilled water in $1000 \mathrm{~mL}$ volumetric flask. A $0.02 \mathrm{M}$ stock solution of salicylic acid was prepared by dissolving $2.76 \mathrm{~g}$ of salicylic acid in distilled water in $1000 \mathrm{~mL}$ volumetric flask. A $0.02 \mathrm{M}$ stock solution of phthalic acid was prepared by dissolving $3.30 \mathrm{~g}$ of phthalic acid in distilled water in 1000 $\mathrm{mL}$ volumetric flask. A $0.02 \mathrm{M}$ stock solution of $o$-toluic acid was prepared by dissolving $2.72 \mathrm{~g}$ of $o$-toluic acid in distilled water in $1000 \mathrm{~mL}$ volumetric flask. The concentration of solutes present in stock solutions were standardized by titrating against standard solution of sodium hydroxide.

Characterization: The surface area, pore volume and pore size of adsorbent GAC was estimated by AMINCO porosity meter (M/s. R\&D, A.C.C. Ltd., Mumbai, India). The morphology of GAC was observed by using scanning electron microscopy (Cambridge $5250 \mathrm{MK} 3$ model). The concentration of adsorbate in solution was estimated by UV adsorption using SPEKTROMOM 210 (Hungarian Optical Works, Budapest, Hungry).

Evaluation of adsorption equilibrium: The experimental set up for evaluation of adsorption equilibrium is shown in Fig. 1. Electrical power supply for all appliances was obtained through a 1 and $5 \mathrm{kVA}$ voltage stabilizer- auto set servo controlled electronic stroboscope (M/s Toshniwal Pvt. Ltd., Mumbai, India). A water thermostat was constructed using $45 \mathrm{~L}$ plastic container. The water bath was stirred vigorously with the help of a stirrer.
The temperature of bath was controlled with the help of contact thermometer through an electric relay. The accuracy in temperature regulation was around $\pm 0.2^{\circ} \mathrm{C}$. The bath was heated by a $1000 \mathrm{~W}$ immersion heater. The accurate bath temperatures were recorded on calibrated thermometer with an accuracy of $\pm 0.1{ }^{\circ} \mathrm{C}$.

For the equilibrium runs, $1 \mathrm{~L}$ round bottom flask containing $500 \mathrm{~mL}$ of distilled water was immersed in the thermostat bath. The contents were constantly stirred at $1000 \mathrm{rpm}$ and allowed to attain the bath temperature, which is around 20-30 min. The impeller used for stirring the experimental solution was fabricated out of $6 \mathrm{~mm}$ glass rod with simple Teflon or nylon peddle fitted to its lower end. In such a way, it is used to move freely about axis of the rod but could not slip out. The length of paddle to the diameter of reactor containing the solution to be stirred and should lie in between 2 to $5 \mathrm{~cm}$.

After desired temperature of $30^{\circ} \mathrm{C}$ was reached, a $0.5 \mathrm{~g}$ of granular activated carbon sample was introduced into the initial concentration of stock solution and stirred with 1000 $\mathrm{rpm}$. The stirring was continued till the concentration of the aqueous phase showed no detectable change as measured by UV absorbance. Experiments were continued for $5 \mathrm{~h}$ in order to ensure complete equilibrium. The GAC/adsorbate solution ratio by volume was kept constant at $0.50 \mathrm{~g} / 500 \mathrm{~mL}$ in all equilibrium experiments.

For a bi-solute system, a similar concentration range of stock solution of constituent solute in equal concentrations were added. Rest of the experimental set up and method was same as above stated.

Evaluation of adsorption kinetics: The experimental set up for adsorption kinetic study is shown in Fig. 2. The experi-

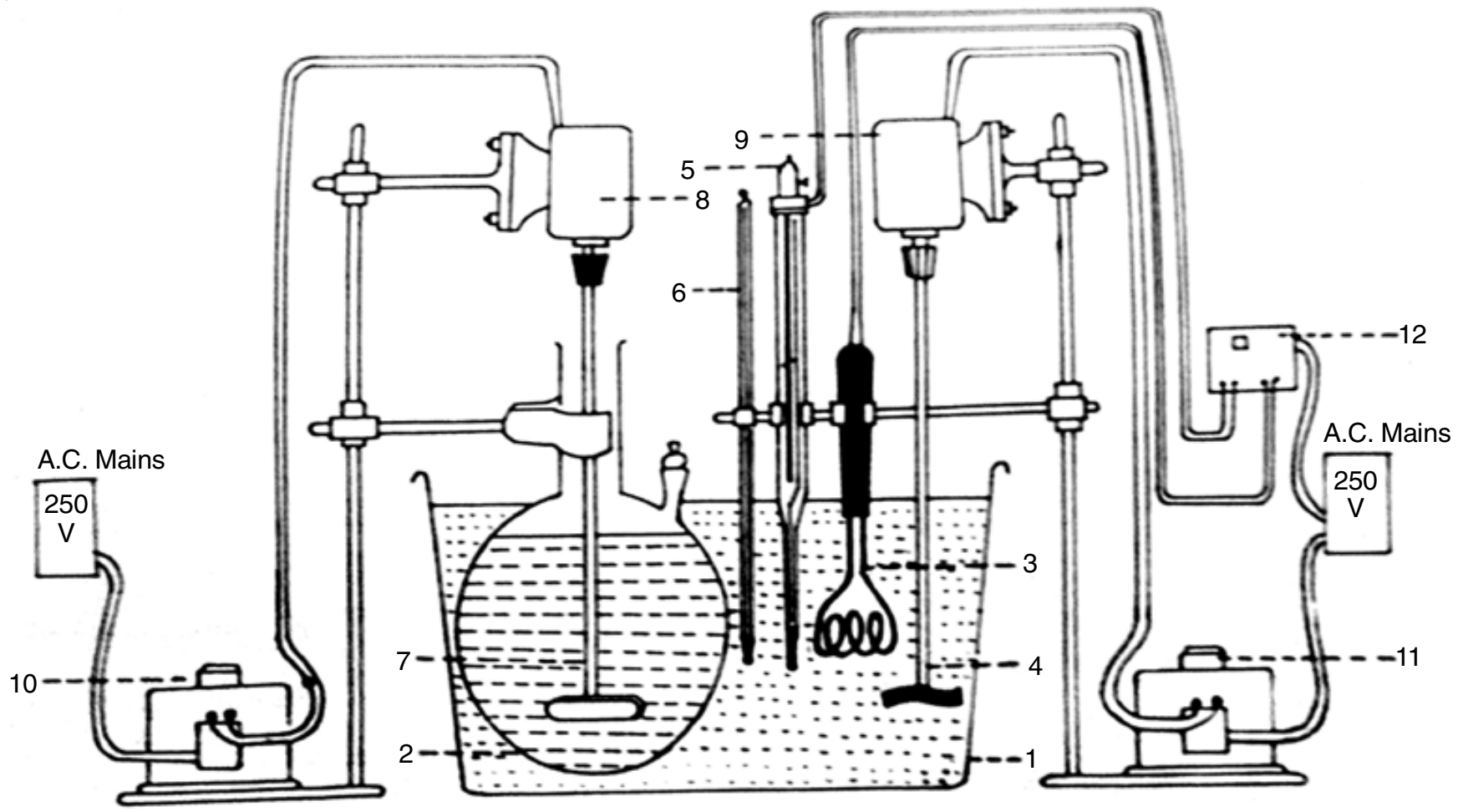

1-Plastic bath, 2-Round bottom flask with side neck, 3-Immersion heater, 4-Metal stirrer, 5-Contact thermometer, 6-Thermometer, 7-Nylon stirrer, 8\&9-Motors, 10\&11-Dimer stand, 12-Electronics relay

Fig. 1. Experimental set up for evaluation of adsorption equilibrium 


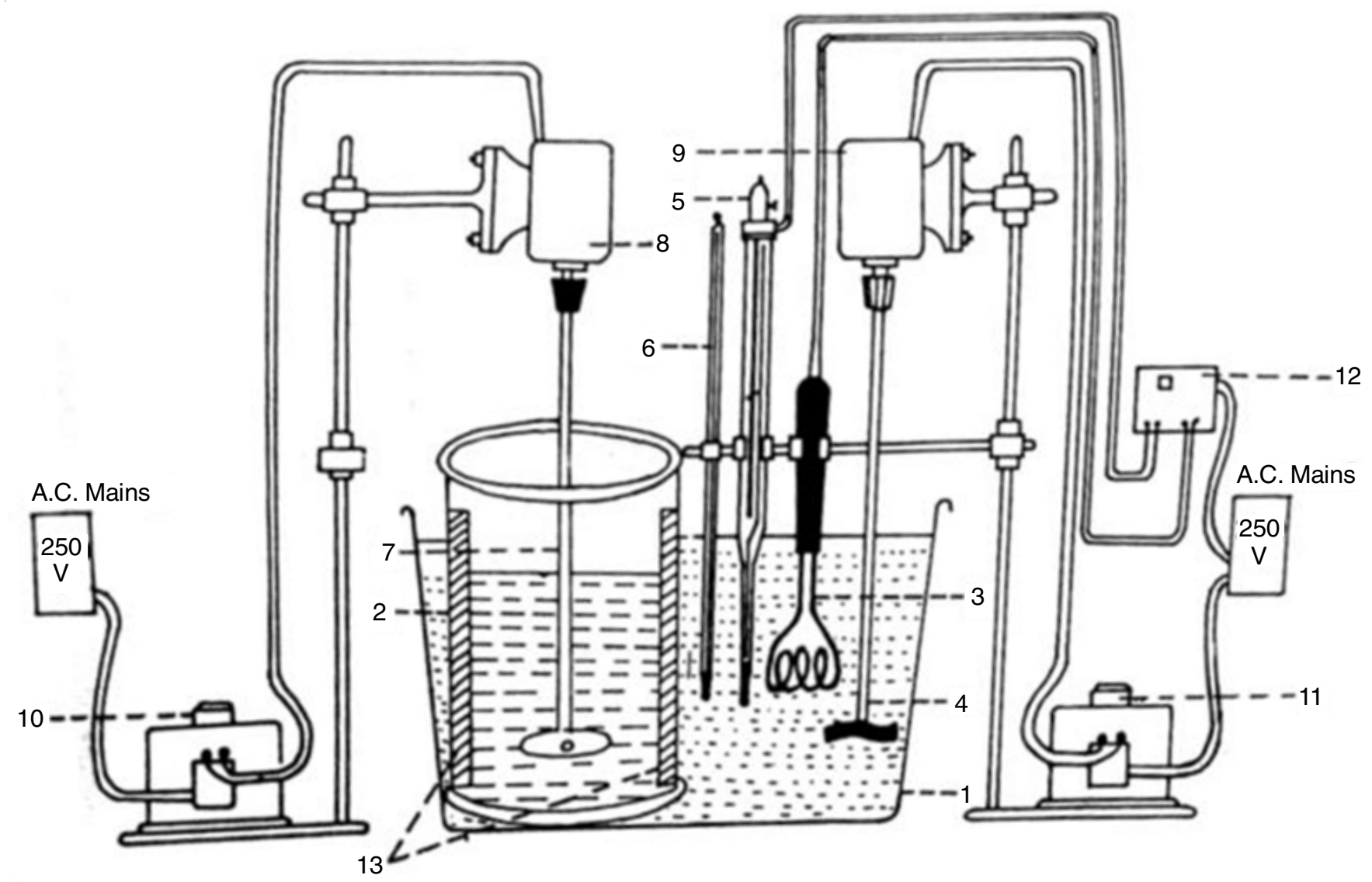

1-Water bath, 2-Reactor, 3-Immersion heater, 4-Metal stirrer, 5-Contact thermometer, 6-Thermometer,

7-Nylo stirrer, 8\&9-Motors, 10\&11-Immerstats, 12-Electronic relay, 13-Baffles

Fig. 2. Experimental set up for adsorption kinetic studies

mental unit consist of a batch reactor of $8 \mathrm{~L}$ capacity and made up of plexi-glass and fitted with baffle. The GAC adsorbate system was stirred by the bladed impeller assembly having length of $7 \mathrm{~cm}$ and breadth $1.5 \mathrm{~cm}$. The solution for kinetics runs consists of $4 \mathrm{~L}$ in volume and was prepared by adding appropriate amounts of stock solution in distilled water. Then GAC (2 g) was introduced into the solution at a given time. At every desired interval of time, $5 \mathrm{~mL}$ of solution was withdrawn and the concentration of adsorbate in the aqueous phase was estimated by UV analysis.

Bi-solute adsorption experiment: While selection of bisolute adsorption experiments solutes were selected so that respective adsorption was sufficiently apart so as to permit their simultaneous quantitative estimation.

Irreversibility of adsorption: In order to check the irreversibility of adsorption, the adsorbent at the end of a typical kinetic was filtered off and separated from the adsorbate solution. It was then washed repeatedly with fresh distilled water till the superficial adhering adsorbate solution was completely as judged from UV absorbance of washings. The washed adsorbent was then reintroduced into exactly the same quantity of distilled water as used in the kinetics run and stirred for $5 \mathrm{~h}$. The UV absorbance was monitored at different set interval of time.

Solubility of compounds: Even though the solubility of benzoic acid and its derivatives under study in water is available in the literature, still the solubility behaviour at the experimental conditions which is required in the present studies is not adequate.
Hence solubility studies have been carried out. In brief, in a $500 \mathrm{~mL}$ distilled water in round bottom flask, a compound was added and the solution was stirred continuously for $8 \mathrm{~h}$ at $30^{\circ} \mathrm{C}$. The stirred solution was allowed to settle for $2 \mathrm{~h}$. Suspended solid particles were removed by filtration. The saturated solution of adsorbate so obtained was diluted with distilled water and its concentration was determined by UV spectroscopy.

\section{RESULTS AND DISCUSSION}

In the present work, a single and multi-component adsorption equilibrium and kinetic studies have been carried out using benzoic acid and its $o$-derivatives (salicylic acid, phthalic acid and $o$-toluic acid. The solubility of these compounds and their stability in water were also taken into account.

Surface area, pore size and morphology analysis: Granular activated carbon (GAC) was subjected to pore size distribution and surface area analysis. BET-surface area of GAC was found to be $998 \mathrm{~m}^{2} / \mathrm{g}$, the particle density $0.7950 \mathrm{~g} /$ $\mathrm{cm}^{3}$, pore volume $0.825 \mathrm{~cm}^{3} / \mathrm{g}$ and the pore diameter less than 20 AU was observed.

The scanning electron micrograph (SEM) of GAC is shown in Fig. 3. SEM analysis of GAC showed a loosely packed structure with lots of cavities, cracks, irregular protrusion and widely dispersed pores. Presence of high ash and mineral contents is causing the loose packing as can be seen from tiny particulate material in micrographs. The high ash and mineral contents lead to higher fragile structure. 

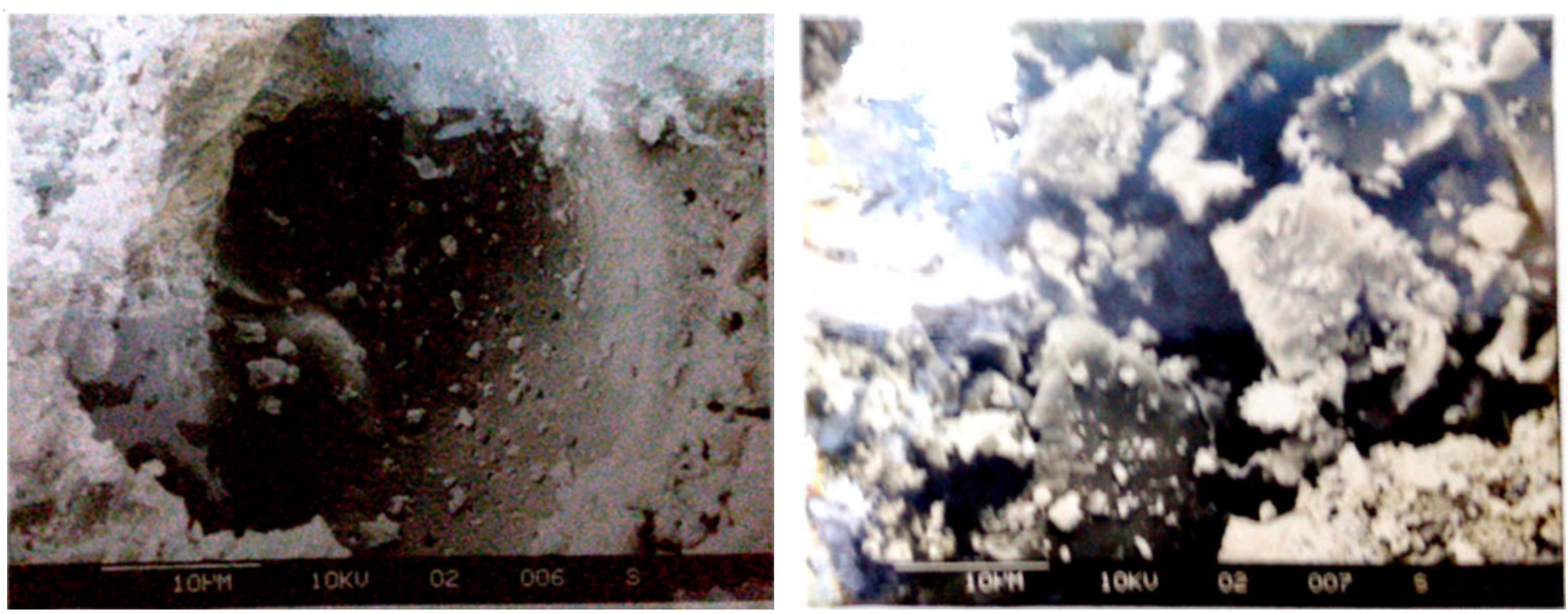

Fig. 3. Scanning electron micrograph of granular activated carbon (GAC)

Proximate analysis of GAC: A proximate analysis of granular activated carbon was carried out and it was observed that GAC comprises of $1.9 \%$ moisture, $6.1 \%$ ash, $2.7 \%$ volatile matter, $89.3 \%$ of fixed carbon, $6.71 \%$ of mineral matter.

Ultimate analysis of GAC: It was observed that $94.04 \%$ of carbon and $0.29 \%$ of hydrogen was present.

UV adsorption studies: For all adsorbates, a plot of adsorbate concentration versus UV absorbance at its maximum absorbance were studied and Beer's law was found to be followed. The molar extinction coefficient was obtained for all the adsorbents. The molar absorptivity for benzoic acid at wavelength of $269 \mathrm{~nm}$ was found to be $775 \mathrm{M}^{-1} \mathrm{~cm}^{-1}$, for salicylic acid at $320 \mathrm{~nm}$ was found to be $3032 \mathrm{M}^{-1} \mathrm{~cm}^{-1}$, for phthalic acid at $279 \mathrm{~nm}$ was found to be $1282 \mathrm{M}^{-1} \mathrm{~cm}^{-1}$ and for $o$-toluic acid was found to be $1031 \mathrm{M}^{-1} \mathrm{~cm}^{-1}$ at $278 \mathrm{~nm}$.

Adsorption equilibrium studies: One of the important adsorption isotherms is Langmuir adsorption isotherm, accordingly maximum adsorption corresponds to a saturated monolayer of adsorbate molecule on adsorbent surface. The energy of adsorption is constant and that there is no transmigration of adsorbate in the plane of the surface.

The equation can be expressed as follows:

$$
\begin{gathered}
\mathrm{Q}_{\mathrm{e}}=\frac{\mathrm{Q}_{\mathrm{o}} \mathrm{bC}_{\mathrm{e}}}{1+\mathrm{bC}_{\mathrm{e}}} \\
\frac{1}{\mathrm{Q}_{\mathrm{e}}}=\frac{1}{\mathrm{Q}_{\mathrm{o}} \mathrm{bC}}+\frac{1}{\mathrm{Q}_{\mathrm{o}}}
\end{gathered}
$$

where, $\mathrm{Q}_{\mathrm{e}}=$ amount of adsorbed solute per unit weight of adsorbent at equilibrium ( $\mathrm{mol} / \mathrm{g}) ; \mathrm{C}_{\mathrm{e}}=$ equilibrium concentration of adsorbate in solution $(\mathrm{mol} / \mathrm{L}) ; \mathrm{Q}_{\mathrm{o}}=$ monolayer capacity of adsorbent $(\mathrm{mol} / \mathrm{g}) ; \mathrm{b}=$ Langmuir constant.

If plot of $1 / \mathrm{Q}_{\mathrm{e}} v s .1 / \mathrm{C}_{\mathrm{e}}$ is linear implies that Langmuir adsorption isotherm is operative.

Another important adsorption isotherm is Freundlich adsorption isotherm. The equation for Freundlich adsorption isotherm is represent as follows:

$$
\log \mathrm{Q}_{\mathrm{e}}=\log \mathrm{k}+\mathrm{n} \log \mathrm{C}_{\mathrm{e}}
$$

If plot of $\log \mathrm{Q}_{\mathrm{e}} v s . \log \mathrm{C}_{\mathrm{e}}$ is linear which implies that the Freundlich adsorption isotherm does hold.
Single solute adsorption: The adsorption equilibrium isotherm plots for all adsorbates on GAC of mesh size $12 \mathrm{X} 16$ are shown in Fig. 4, which indicate a typical type 1 favourable isotherm [18].

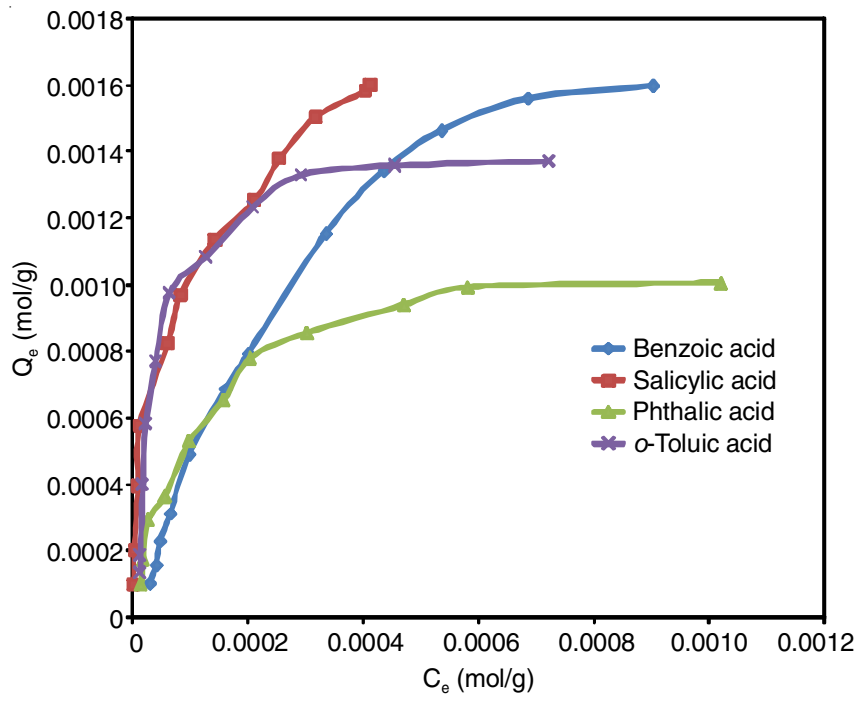

Fig. 4. Adsorption equilibrium isotherm plots on granular activated carbon of mesh size $12 \mathrm{X} 16$

In the present investigation, an evaluation was made to determine if the experimental data for different adsorbate could be fitted to either the Langmuir or Freundlich equations. The results from this analysis indicated that the experimental data did not adhere to either of these two models completely. However, the data could be fitted to either model prided one was selective in the equilibrium concentration range to be used in the analysis. Table-1 gives the complete isotherm equation, Langmuir, Freundlich and BET constant as well as the equilibrium adsorbate concentration $\mathrm{C}_{\mathrm{e}}$ range over which the given system adhere to the linearity of relation for all adsorbentadsorbate systems. The values of regression coefficient ( $r$ ) for all the adsorbent-adsorbate systems was found to be around 0.99, indicating a good mathematical fit.

Multi-solute adsorption equilibrium: The adsorption equilibrium obtained for various bi-solute-adsorbent system 


\begin{tabular}{|c|c|c|c|c|c|c|c|c|c|c|c|c|}
\hline \multirow{3}{*}{$\begin{array}{l}\text { System } \\
\text { (mesh } \\
\text { size) }\end{array}$} & \multicolumn{12}{|c|}{$\begin{array}{c}\text { TABLE-1 } \\
\text { LANGMUIR, FREUNDLICH AND BET ISOTHERM EQUATION AND DATA FOR SINGLE SOLUTE SYSTEM }\end{array}$} \\
\hline & \multicolumn{4}{|c|}{ Langmuir isotherm } & \multicolumn{3}{|c|}{ Freundlich isotherm } & \multicolumn{5}{|c|}{ BET isotherm } \\
\hline & $\begin{array}{l}\text { Equation } \\
\left(Q_{e}=\right)\end{array}$ & $\mathrm{r}$ & $\begin{array}{c}\mathrm{Q} \\
(\mathrm{mmol} / \mathrm{g})\end{array}$ & $\begin{array}{c}\mathrm{C}_{\mathrm{e}} \\
(\mathrm{mmol} / \mathrm{L})\end{array}$ & $\begin{array}{c}\text { Equation } \\
\left(\mathrm{Q}_{\mathrm{e}}=\right)\end{array}$ & $\mathrm{r}$ & $\begin{array}{c}\mathrm{C}_{\mathrm{e}} \\
(\mathrm{mmol} / \mathrm{L})\end{array}$ & Slope & $\begin{array}{c}\text { Inter- } \\
\text { cept }\end{array}$ & $\mathrm{r}$ & $\mathrm{z}$ & $\begin{array}{c}\mathrm{Q} \\
(\mathrm{mmol} / \mathrm{g})\end{array}$ \\
\hline $\begin{array}{l}\text { Benzoic } \\
\text { acid } \\
(12 X 16)\end{array}$ & $\frac{5.571 \mathrm{C}_{\mathrm{e}}}{1+1962 \mathrm{C}_{\mathrm{e}}}$ & 0.99 & 2.84 & $0.065-0.9$ & $9341 C_{\mathrm{e}}^{0.8326}$ & 0.99 & $0.047-$ & 349.28 & 6.21 & 0.99 & 57.23 & 0.28 \\
\hline $\begin{array}{l}\text { Salicylic } \\
\text { acid } \\
(12 X 16)\end{array}$ & $\frac{24.21 \mathrm{C}_{\mathrm{e}}}{1+135412 \mathrm{C}_{\mathrm{e}}}$ & 0.99 & 1.79 & $0.08-0.4$ & $702 \mathrm{C}_{\mathrm{e}}^{0.5157}$ & 0.98 & $\begin{array}{c}0.014- \\
0.604\end{array}$ & 519.53 & 3.119 & 0.99 & 167.4 & 0.1914 \\
\hline $\begin{array}{l}\text { Phthalic } \\
\text { acid } \\
(12 X 16)\end{array}$ & $\frac{11.7 \mathrm{C}_{\mathrm{e}}}{1+12812 \mathrm{C}_{\mathrm{e}}}$ & 0.99 & 0.9 & $\begin{array}{l}0.093- \\
1.35\end{array}$ & $411.9 \mathrm{C}_{\mathrm{e}}^{0.4797}$ & 0.99 & $\begin{array}{l}0.017- \\
0.555\end{array}$ & 883.11 & 2.341 & 0.99 & 378.17 & 1.129 \\
\hline $\begin{array}{l}o \text {-Toluic } \\
\text { acid } \\
(12 \times 16)\end{array}$ & $\frac{58.139 \mathrm{C}_{\mathrm{e}}}{1+38224 \mathrm{C}_{\mathrm{e}}}$ & 0.97 & 1.3 & $\begin{array}{l}0.026- \\
0.55\end{array}$ & $58 \mathrm{C}_{\mathrm{e}}^{0.1903}$ & 0.97 & 0.04-0.69 & 758.82 & 0.244 & 0.99 & 360.9 & 1.317 \\
\hline $\begin{array}{l}\text { Benzoic } \\
\text { acid } \\
(25 X 44)\end{array}$ & $\frac{7.396 C_{e}}{1+2506 C_{e}}$ & 0.99 & 2.952 & $\begin{array}{c}0.065- \\
0.46\end{array}$ & $3800 C_{e}^{0.713}$ & 0.98 & $\begin{array}{c}0.047- \\
0.486\end{array}$ & 378.13 & 0.493 & 0.96 & 77.96 & 0.26106 \\
\hline $\begin{array}{l}\text { Salicylic } \\
\text { acid } \\
(25 \times 44)\end{array}$ & $\frac{28.735 \mathrm{C}_{\mathrm{e}}}{1+15616 \mathrm{C}_{\mathrm{e}}}$ & 0.99 & 1.8400 & $\begin{array}{c}0.027- \\
0.27\end{array}$ & $483 \mathrm{C}_{\mathrm{e}}^{0.4152}$ & 0.99 & $\begin{array}{c}0.008- \\
0.28\end{array}$ & 555.02 & 1.64 & 0.99 & 339.3 & 1.796 \\
\hline $\begin{array}{l}\text { Phthalic } \\
\text { acid } \\
(25 \times 44)\end{array}$ & $\frac{23.526 \mathrm{C}_{\mathrm{e}}}{1+23292 \mathrm{C}_{\mathrm{e}}}$ & 0.97 & 1.01 & $\begin{array}{c}0.039- \\
0.78\end{array}$ & $60.9 C_{e}^{0.2437}$ & 0.98 & $\begin{array}{c}0.039- \\
0.98\end{array}$ & 824.64 & 2.57 & 0.99 & 320.86 & 1.213 \\
\hline $\begin{array}{l}\text { Benzoic } \\
\text { acid } \\
(72 X 100)\end{array}$ & $\frac{7.4682 \mathrm{C}_{\mathrm{e}}}{1+2440 \mathrm{C}_{\mathrm{e}}}$ & 0.99 & 3.06 & $\begin{array}{c}0.019- \\
3.88\end{array}$ & $6284 \mathrm{C}_{\mathrm{e}}^{0.7614}$ & 0.99 & $\begin{array}{c}0.019- \\
0.388\end{array}$ & 369.3 & 4.46 & 0.97 & 83.82 & 2.673 \\
\hline $\begin{array}{l}\text { Salicylic } \\
\text { acid } \\
(72 X 100)\end{array}$ & $\frac{10.51 \mathrm{C}_{\mathrm{e}}}{1+5111 \mathrm{C}_{\mathrm{e}}}$ & 0.99 & 2.053 & $\begin{array}{c}0.051- \\
0.272\end{array}$ & $4071 \mathrm{C}_{\mathrm{e}}^{0.7016}$ & 0.96 & $\begin{array}{c}0.051- \\
0.304\end{array}$ & 518.72 & 5.180 & 0.93 & 101.11 & 1.908 \\
\hline $\begin{array}{l}\text { Phthalic } \\
\text { acid } \\
\text { (72X100) }\end{array}$ & $\frac{2.98 \mathrm{C}_{\mathrm{e}}}{1+2675 \mathrm{C}_{\mathrm{e}}}$ & 0.93 & 1.114 & $\begin{array}{c}0.017- \\
0.45\end{array}$ & $196 C_{e}^{0.3355}$ & 0.98 & $\begin{array}{c}0.017- \\
0.62\end{array}$ & 709.39 & 1.188 & 0.99 & 597.33 & 1.400 \\
\hline
\end{tabular}

is shown in Fig. 5. The removal rate for all the components was much higher for bi-solute systems. It is assumed that various solutes diffuse independently of one another and the competitive effects are taken into account only through the adsorption isotherm. Thus to evaluate the competitive effect of various adsorbates, the multisolute adsorption equilibrium data was analyzed by Langmuir model. For the evaluation of $\mathrm{Q}_{\mathrm{o}}$ and $\mathrm{b}$ values, the adsorption equilibrium data for all components in bi-solute system were treated independently to verify the validity of Langmuir equation. The change in the adsorptive capacity of an adsorbate on a particular grade of adsorbent when present in a multisolute system versus adsorptive capacity of the solute from its single solute system was compared to observe the competitive effects. The obtained values of $Q_{o}$ and constant $b$, for all the bi-solute systems are reported in Table- 2 .
If we compare the monolayer capacity of each adsorbate on a particular adsorbent, then it becomes apparent that monolayer adsorption capacity for each adsorbate in a solute system reduced relative to its value in the single solute system but the cumulative adsorption capacity for multisolute system were higher than those for single solute system. In mixture, the competitive effects are more pronounced as the number of solute increase and the total adsorption capacity is thus enhanced due to increased cumulative adsorbate concentration.

The monolayer capacity of each adsorbate reduced relative to its value in single solute system. The comparison of monolayer capacity obtained from competitive bi-solute adsorption studies indicate that the activated carbon surface has slightly greater affinity for benzoic acid as compared to salicyclic acid, as about $46-49 \%$ of the total cumulative monolayer capacity
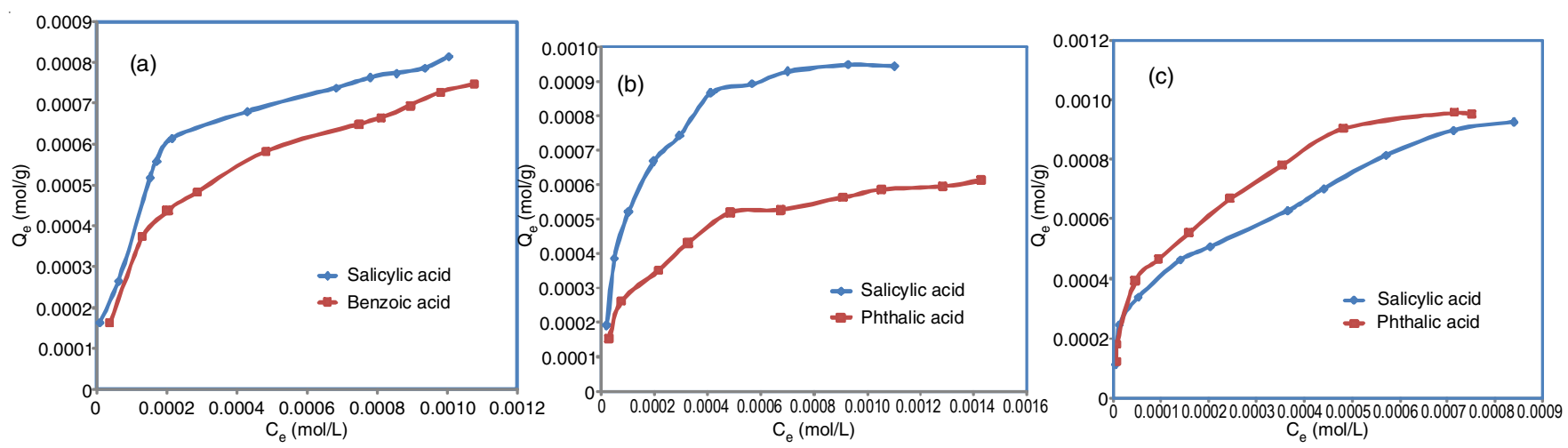

Fig. 5. Adsorption equilibrium obtained for bi-solute-adsorbent systems 
TABLE-2

LANGMUIR CONSTANTS FOR BISOLUTE SYSTEM

\begin{tabular}{|c|c|c|c|c|c|c|}
\hline System (mesh size) & $\begin{array}{c}\mathrm{Q}_{0} 1 \times 10^{-4} \\
(\mathrm{~mol} / \mathrm{g})\end{array}$ & b1 & $\begin{array}{c}\mathrm{Q}_{0} 1 \times 10^{-4} \\
(\mathrm{~mol} / \mathrm{g})\end{array}$ & b2 & $\begin{array}{c}\left(\mathrm{Q}_{\mathrm{o}} 1+\mathrm{Q}_{\mathrm{o}} 2\right) \times \\
10^{-4}(\mathrm{Mol} / \mathrm{g})\end{array}$ & $(b 1+b 2)$ \\
\hline Salicylic acid-Benzoic acid (12X16) & 14.48 & 9950 & 15.70 & 5683 & 30.18 & 15633 \\
\hline Salicylic acid-Benzoic acid (25X44) & 12.51 & 8770 & 12.19 & 4729 & 24.71 & 13499 \\
\hline Salicylic acid-Benzoic acid (72X100)) & 15.14 & 5640 & 13.37 & 1133 & 28.51 & 6774 \\
\hline Salicylic acid-Phthalic acid (12X16) & 10.52 & 9387 & 6.89 & 4795 & 17.51 & 14182 \\
\hline Salicylic acid-Phthalic acid (25X44) & 12.66 & 9723 & 6.15 & 14198 & 18.81 & 23917 \\
\hline Salicylic acid-Phthalic acid (72X100) & 17.21 & 3450 & 11.38 & 7668 & 28.60 & 11119 \\
\hline Salicylic acid-o-Toluic acid (12X16) & 12.31 & 3248 & 12.03 & 5194 & 24.34 & 8442 \\
\hline Salicylic acid-o-Toluic acid (25X44) & - & - & - & - & - & - \\
\hline Salicylic acid-o-Toluic acid (72X100) & _- & - & _- & _- & _ & - \\
\hline
\end{tabular}

$\left(\mathrm{Q}_{0} 1+\mathrm{Q}_{0} 2\right)$ was occupied salicylic acid about 51-54\% of total cumulative monolayer capacity was occupied by benzoic acid. Similarly, a competitive adsorption isotherm of bi-solute systems salicylic acid-o-toluic acid on GAC shows that these adsorbate compete with almost same affinity for the available carbon surface; while in case of salicylic acid-phthalic acid; salicylic acid is clearly adsorbed more preferentially over its competitor. In case of single solute adsorbate-adsorbent systems; salicylic acid was adsorbed to larger extent as compared to phthalic acid.

Adsorption kinetics: The comparative adsorption kinetics plot for all adsorbates is shown in Fig. 6. The study indicates that the adsorbates were removed rapidly from the aqueous phase within the first hour of contact. For mesh size 12X16 of GAC was about $60-75 \%$ of solute was removed in $1 \mathrm{~h}$ whereas for mesh size $25 \mathrm{X} 44$, the removal was $65-85 \%$. In case of very fine fraction of $72 \times 100$ mesh more than $85 \%$ adsorbate was removed in first $5 \mathrm{~min}$ only. It is obvious that particle grinding opens up some sealed or narrow pores previously inaccessible and exposes the large surface are on GAC leading to rapid adsorption and slight increase in specific surface area. In case of competitive adsorption involving two solutes, it is assumed that the various solutes diffuse independently of one another and the comparative effects are taken into account only through the adsorption isotherm rate constant found in this manner are purely phenomenological depending upon the rate of adsorption and diffusion. The individual process like adsorption, desorption and molecular diffusion are all coupled together and represented by overall rate constant. The adsorption kinetic data was fitted in the following equation:

$$
\frac{\ln \left(\mathrm{C}-\mathrm{C}_{\mathrm{e}}\right)}{\mathrm{C}+\mathrm{D}}=-\mathrm{kt}
$$

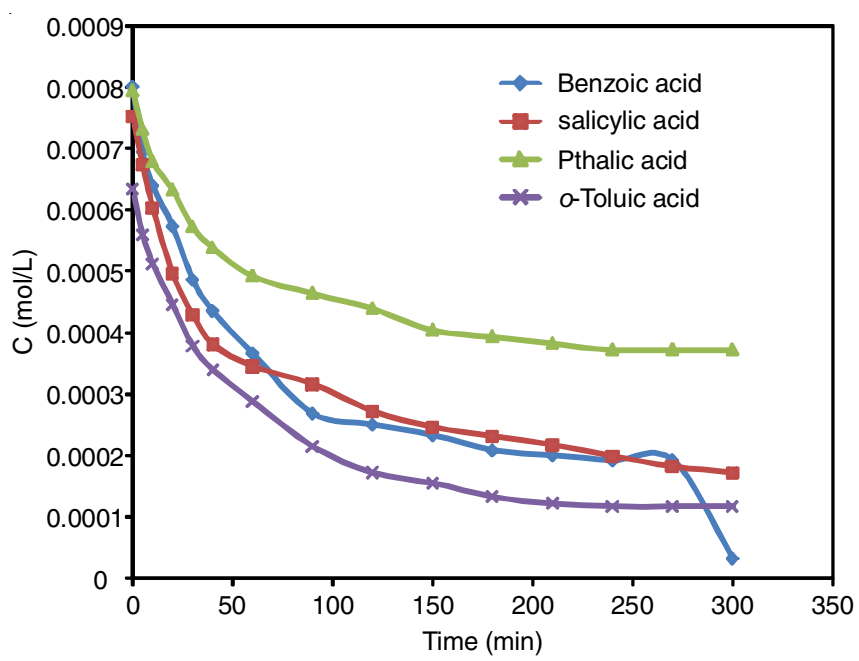

Fig. 6. Comparative kinetics plots for adsorption of all adsorbates

where, $\mathrm{D}=\mathrm{C}_{\mathrm{o}} / \mathrm{K} \mathrm{C}_{\mathrm{e}}$.

The linear regression analysis of data gave high corelation, coefficient in the range 0.97-0.995, indicating a good linear fit. Table-3 shows the value of adsorption rate constant for various single and multisolute systems.

Adsorption kinetics studies for single solute-adsorbent system shows that the adsorbate removal rate for the carboxylic acid decreases as their solubility in aqueous phase increases. The adsorbate removal rates were found in order benzoic acid $>$ salicylic acid $>o$-toluic acid $>$ phthalic acid. During the competitive adsorption, the more hydrophobic adsorbates was removed at a faster rate as compared to the less hydrophobic one. The removal rate of individual components decreased as compared to their rate from single solute systems but the sum of the removal rate for all the components was much higher

TABLE-3

ADSORPTION RATE CONSTANT (K) FOR SINGLE SOLUTE SYSTEM

\begin{tabular}{|c|c|c|c|c|c|c|}
\hline System & $\mathrm{C}_{\mathrm{o}}(\mathrm{mmol} / \mathrm{L})$ & $\mathrm{k}$ & Intercept & $\mathrm{r}$ & $\mathrm{K}$ & $\mathrm{K}^{\prime}$ \\
\hline \multicolumn{7}{|c|}{ Single solute system } \\
\hline Benzoic acid & 0.800 & 0.01840 & -5.2956 & 0.9912 & 4.5640 & 0.004032 \\
\hline Salicylic acid & 0.210 & 0.01935 & -7.0990 & 0.9870 & 12.0040 & 0.001612 \\
\hline Phthalic acid & 0.790 & 0.01630 & -5.0433 & 0.9942 & 12.8200 & 0.001271 \\
\hline$o$-Toluic acid & 0.634 & 0.01990 & -5.6289 & 0.9917 & 58.1390 & 0.003422 \\
\hline \multicolumn{7}{|c|}{ Bi-component system } \\
\hline Salicylic acid- & 0.200 & 0.01664 & -6.2500 & 0.9828 & 12.0040 & 0.001386 \\
\hline Benzoic acid & 0.360 & 0.01476 & -6.9500 & 0.9837 & 4.56400 & 0.003234 \\
\hline Salicylic acid- & 0.212 & 0.01850 & -6.1956 & 0.9929 & 12.0040 & 0.001541 \\
\hline Phthalic acid & 0.155 & 0.01148 & -5.5390 & 0.9987 & 12.8200 & 0.000895 \\
\hline
\end{tabular}


for bi-solute systems (Table-3). In mixture, the competitive effects are more pronounced the number of solute increases and the total adsorption capacity was thus enhanced due to increased cumulative adsorbate concentration.

According to literature, an increase in initial concentration of solute decreases the time at which the breakthrough appears. The competitive adsorption from mixture of organic may be advantageous or detrimental depending on intended application of the adsorption unit. If the purpose is complete removal of all organics, then presence of other solute is advantageous because of a greater utilization of the adsorbent can be obtained whereas; if the application is to selective removal of a certain organic compound, then the efficiency of GAC will decrease with increase in concentration of the adsorbate solute.

Effect of functional group at ortho-position: A type of functional group present on adsorbate is an important as its size and configuration. The addition of substituent group on adsorbate can manifest itself in several ways. First, the substituent group may alter the solubility of the adsorbate in aqueous solution. Since the solubility is a measure of adsorbate solvent forces of attraction any change in solubility of molecule will influence the adsorbate-adsorbent forces of attraction. Secondly, the adsorbate may interact specially with a compatible functional group present on the carbon surface. Thirdly, the addition of certain functional group to benzoic acid group will alter the electron density of benzene ring. This influence is significant only if $\pi$-electrons of the adsorbate molecule are involved in the mechanism of adsorption. Finally, the substituent group may alter the acidic dissociation constant $\left(\mathrm{pK}_{\mathrm{a}}\right.$ value) carboxylic acid and decides whether or not the adsorbate will be in associated or dissociated form. If one compares the $Q_{0}$ values obtained for all the adsorbate-GAC systems, then monolayer capacity of adsorbate follows the trend benzoic acid > salicylic acid $>o$-toluic acid $>$ phthalic acid.

Effect of molecular weight on adsorption capacity: In case of benzoic acid and its derivatives, monolayer capacity decreased with increase in molecular weight. The adsorption capacity for benzoic acid and its derivatives on GAC with respect to molecular weight is shown in Fig. 7, which revealed that

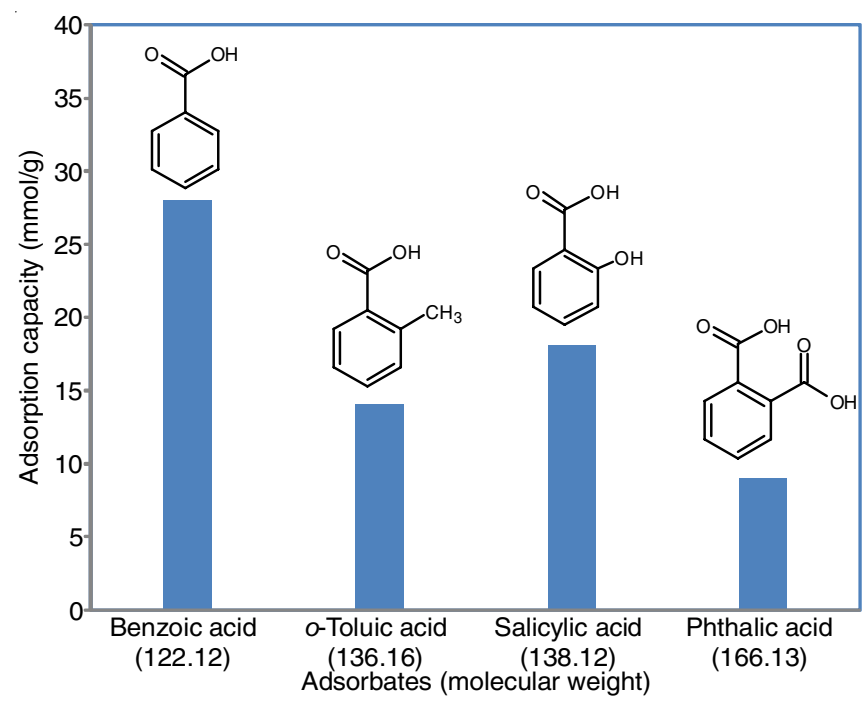

Fig. 7. Adsorption capacity for benzoic acid and its derivatives on granular activated carbon with respect to molecular weight the salicylic acid were absorbed with higher capacity than $o$-toluic acid and phthalic acid.

Effect of solubility of adsorbate: The solubility of adsorbates at experimental conditions was found to be $2.860 \mathrm{mmol} /$ $\mathrm{L}$ for benzoic acid, $1.930 \mathrm{mmol} / \mathrm{L}$ for salicylic acid, 3.968 $\mathrm{mmol} / \mathrm{L}$ for phthalic acid and $0.00790 \mathrm{~mol} / \mathrm{L}$ for $o$-toluic acid. The solubility of adsorbate is also known to affect the overall adsorprtion capacity to the large extent. The pure activated carbon surface is considered to be non-polar and is generally regarded to favour the adsorption of non-polar solutes. Solubility trend of benzoic acid and its derivative follows the order as: phthalic acid $>$ benzoic acid $>$ salicylic acid $>o$-toluic acid. The adsorption isotherm follows the order as: benzoic acid $>$ salicylic acid $>o$-toluic acid $>$ phthalic acid. The observation implies that more hydrophobic solutes are adsorbed to a greater extent from its aqueous solution, which implies that the physicochemical properties associated with adsorbate has an important role in the overall adsorption process.

The possibility of hydrogen bonding between the solute and water molecule has a major effect on the solute adsorption by activated carbon and hence the molecular weight and solubility should not necessarily be considered as a controlling factor. The -OH group to form a hydrogen bond with water, decreasing the solvophobic nature of the solute, whereas any substituent group in benzoic acid molecule might be preventing the formation of hydrogen bond between the solute and solvent, either by forming internal hydrogen bond between - $\mathrm{OH}$ and other substituent group or by offering steric hindrance, thereby increasing the solvo-phobic nature as well as sorption capacity of solute. In case of salicylic acid- $\mathrm{COOH}$ and - $\mathrm{OH}$ group at orthoposition form intramolecular hydrogen bonding thereby increasing the hydrophobic nature of solute and the extent of its adsorption.

The introduction of substituent groups improved the adsorption, which can hinders the possibilities of hydrogen bonding with solvent, water; thereby decrease the hydrophilic character. In case of $o$-toluic acid, the intramolecular hydrogen bonding between $-\mathrm{CH}_{3}$ and -OH group probably replaces the intermolecular hydrogen bond with water, while in case of phthalic acid the introduction of - $\mathrm{COOH}$ group at ortho-position may sterically hinder the - $\mathrm{COOH}$ group from forming the hydrogen bond with the solvent molecule. In case of carboxylic acids - $\mathrm{COOH}$ group or -OH group points towards the surface of water and the aromatic ring points vertically away from the solution. In case of phthalic acid, the lesser adsorption may be because of its two carboxylic group at ortho-position pointing towards the water surface making its affinity towards water stronger.

Competitive adsorption equilibrium: The predicted isotherm by Langmuir equal competition and unequal competition models as well as the extended Freundlich isotherm model. The predicted isotherm from Langmuir model deviated to larger extent. In contrast to this, the extended Freundlich isotherm model fits the experimental fairly well at lower adsorbate equilibrium concentration ranges and tends to show a positive deviation at adsorbate equilibrium concentration values.

For salicyclic acid-benzoic acid system, the extended Freundlich curve for both the adsorbates are lower, while the Langmuir unequal completion curves are higher and the 
Langmuir equal completion curves are much higher than their respective experimental curves. Similar observations were made in the case of other bi-solute systems. The predictions by extended Freundlich isotherm models for most of the bi-solute system were much closer to the experimental isotherm, but the Langmuir equal competition and unequal competition model prediction showed either positive or negative deviation from the experimental plots.

Effect of particle size of GAC on adsorption: The effect of adsorbent particle size on adsorption equilibrium and removal rates were evaluated on three size fraction of GAC (Table-4). The particle sizes chosen were 12X16, 25X44 and 72X100 B.S. mesh size. The single solute adsorption isotherm of benzoic acid, salicylic acid and phthalic acid were determined at various particle size of GAC. The equilibrium data was then analyzed by Langmuir isotherm model. The adsorbent monolayer capacity was estimated by linear regression of the experimental data. According to the results, the monolayer capacity of adsorbate increases with decrease in adsorbent particle size. The monolayer capacity of adsorbate on $72 \mathrm{X} 100$ mesh is about 7-20\% higher and for 25X44 mesh sample about 5-10 \% higher than that for $12 \mathrm{X} 16$ mesh GAC. Thus, an increase in the adsorbent surface area are due to the particle fragmentation and grinding of GAC granules does open up some close channels and pores, which become more accessible to the adsorbate molecules. Similar behaviour was also observed for bi-solute system.

\begin{tabular}{cccc}
\multicolumn{4}{c}{ TABLE-4 } \\
EFFECT OF GAC PARTICLE SIZE ON \\
ADSORPTION CAPACITY $\left(\mathrm{Q}_{\mathrm{o}} \times 10^{-4} \mathrm{~mol} / \mathrm{g}\right)$ AT $30^{\circ} \mathrm{C}$ \\
\hline GAC mesh size & Benzoic acid & Salcylic acid & Phthalic acid \\
\hline $12 \mathrm{X} 16$ & 28.40 & 15.91 & 9.13 \\
25X44 & 29.52 & 18.42 & 10.10 \\
$72 \mathrm{X} 100$ & 30.60 & 20.51 & 11.14 \\
\hline
\end{tabular}

Irreversibility experiments: From the irreversibility experiments, it can be observed that there was no detectable change in transmission values showing that the adsorbate is firmly adsorbed on the adsorbent and the process is irreversible. However, the adsorbent was stirred in spectroscopic grade methanol, the adsorbate was released into the solution showing thereby that the adsorbate could be desorbed from adsorbent by methanol, which is used as for regeneration of GAC.

Stability of adsorbent: The GAC used in experiments were stable during the course of experiments and did not show any change in size during runs.

\section{Conclusion}

The effect of ortho-substitutions to benzoic acid on adsorption behaviour over granular activated carbon (GAC) from its aqueous phase is investigated. The GAC having the surface area of $998 \mathrm{~m}^{2} / \mathrm{g}$ consists of widely dispersed porosity and loose bonded morphology. The experimental isotherm did not adhere to either Freundlich or Langmuir models completely. However, the data could be fitted well to either model if one is selective in the equilibrium concentration range to be used in analysis. The adsorption rate was rapid in the first hour of contact where
$60-80 \%$ of adsorbate is removed followed by a slow approach to equilibrium. Overall adsorption order for benzoic acid and its ortho-derivative its aqueous phase over GAC was found to be benzoic acid $>$ salicylic acid $>o$-toluic acid $>$ phthalic acid. The adsorption capacity and removal rate of individual components detected as relative to its value in single solute systems but the cumulative adsorption capacity and adsorbate removal rate increased for bi-solute system.

\section{CONFLICT OF INTEREST}

The authors declare that there is no conflict of interests regarding the publication of this article.

\section{REFERENCES}

1. G.Z. Kyzas and D.N. Bikiaris, Mar. Drugs, 13, 312 (2015); https://doi.org/10.3390/md13010312.

2. J.-G. Yu, B.-Y. Yue, X.-W. Wu, Q. Liu, F.-P. Jiao, X.-Y. Jiang and X.-Q. Chen, Environ. Sci. Pollut. Res., 23, 5056 (2016); https://doi.org/10.1007/s11356-015-5880-X.

3. Y. John, V.E. David Jr. and D. Mmereki, Int. J. Chem. Eng., 2018, 3975948 (2018); https://doi.org/10.1155/2018/3975948.

4. M.A. Ashraf, Environ. Sci. Pollut. Res., 24, 4223 (2017); https://doi.org/10.1007/s11356-015-5225-9.

5. E. Fattore, R. Fanelli and C. La Vecchia, J. Epidemiol. Community Health, 56, 831 (2002);

https://doi.org/10.1136/jech.56.11.831.

6. L.A. Thompson and W.S. Darwish, J. Toxicol., 2019, 2345283 (2019); https://doi.org/10.1155/2019/2345283.

7. P.S. Pamidimukkala and H. Soni, J. Environ. Chem. Eng., 6, 3135 (2018); https://doi.org/10.1016/j.jece.2018.04.013.

8. S.G. Muntean, M.A. Nistor, E. Muntean, A. Todea, R. Ianos and C. Pacurariu, J. Chem., 2018, 6249821 (2018); https://doi.org/10.1155/2018/6249821.

9. D. Sinha, A. Supong and P.C. Bhomick, Int. J. Hydrol., 1, 91 (2017); https://doi.org/10.15406/ijh.2017.01.00017.

10. K. Sartova, E. Omurzak, G. Kambarova, I. Dzhumaev and Z. Abdullaeva, Diamond Rel. Mater., 91, 90 (2019); https://doi.org/10.1016/j.diamond.2018.11.011.

11. H. Wang, B. Wang, J. Li and T. Zhu, Sep. Purif. Technol., 209, 535 (2019); https://doi.org/10.1016/j.seppur.2018.07.076.

12. F. Suo, X. Liu, C. Li, M. Yuan, B. Zhang, J. Wang, Y. Ma, Z. Lai and M. Ji, Int. J. Biol. Macromol., 121, 806 (2019); https://doi.org/10.1016/j.ijbiomac.2018.10.132.

13. B. Li and C. Ma, Energy Procedia, 153, 471 (2018); https://doi.org/10.1016/j.egypro.2018.10.063.

14. H.-J. Kim and Y.-K. Han, Curr. Appl. Phys., 16, 1437 (2016); https://doi.org/10.1016/j.cap.2016.08.009.

15. N. Dejang, O. Somprasit and S. Chindaruksa, Energy Procedia, 79, 727 (2015); https://doi.org/10.1016/j.egypro.2015.11.556.

16. M. Açýkyýldýz, A. Gürses and S. Karaca, Micropor. Mesopor. Mater., 198, 45 (2014); https://doi.org/10.1016/j.micromeso.2014.07.018.

17. C.L. Chuang, P.C. Chiang and E.E. Chang, Chemosphere, 53, 17 (2003); https://doi.org/10.1016/S0045-6535(03)00357-6.

18. A. Derylo-Marczewska, M. Blachnio, A.W. Marczewski, M. Seczkowska and B. Tarasiuk, Chemosphere, 214, 349 (2019); https://doi.org/10.1016/j.chemosphere.2018.09.088.

19. L.G. Wade, Organic Chemistry, Pearson Education Limited: Harlow, p. 985 (2014).

20. J. Péc, M. Strmenova, E. Palencarova, R. Pullmann, S. Funiakova, P. Visnovsky, J. Buchanec and Z. Lazarova, Cutis, 50, 307 (1992). 